\title{
Audit \\ Validity of fine needle aspiration cytology in the diagnosis of salivary gland lesions Bopagoda TPM ${ }^{1}$, Williams $H^{2}$
}

\begin{abstract}
Objective: To determine the accuracy of fine needle aspiration cytology (FNAC) in the diagnosis of salivary gland lesions.
\end{abstract}

Method: A retrospective analysis of 96 FNAC and corresponding histology obtained from salivary gland lesions was done. Sensitivity, specificity, accuracy, positive predictive value, negative predictive value, likely hood ratio and cyto-histological concordance were calculated.

Results: Benign lesions accounted for $79.2 \%$ and 3.1\% were malignant. The cyto-histological concordance $(\mathrm{C})$ for benign and malignant lesions was $77 \%$ and $18 \%$ respectively and nonconcordance (NC) was $22.6 \%$ and $9 \%$ respectively. The overall rate of deferred diagnosis (DD) was $17.7 \%, 15.4 \%$ for non-neoplastic lesions, $45.5 \%$ for malignant tumours and $12.7 \%$ for benign tumours. When the cases of deferred diagnosis were included, the diagnostic accuracy, sensitivity and specificity of the FNAC in identifying malignancy were $97 \%, 27 \%$ and $87 \%$ respectively. When cases of deferred diagnosis were excluded the diagnostic accuracy, sensitivity, specificity, positive and negative predictive value and likely hood ratio were $96.2 \%$, $50 \%, 100 \%, 100 \%, 96 \%$ and $50 \%$ respectively.

Conclusion: The diagnostic accuracy is comparable to several of the other studies. However the diagnostic difficulties due to the presence of low grade malignancy with minimal cellular atypia, existence of various histological types and coexistence of more than one tumour type need to be overcome. To improve the accuracy of diagnosis it is necessary to re-aspirate the solid areas after cyst fluid aspiration, preferably under image guidance.

Key words: Salivary gland, neoplasms, diagnostic accuracy

\section{Introduction}

The histopathology of salivary gland tumours is extremely varied and complex (1-7). Distinguishing neoplastic from nonneoplastic and benign from malignant tumours is important, since salivary gland neoplasms are almost always treated surgically (4). Furthermore, metastasis or secondary deposits to salivary glands are common and correct diagnosis of a secondary neoplasm is important to avoid unnecessary surgery $(6,8)$. The value of FNAC

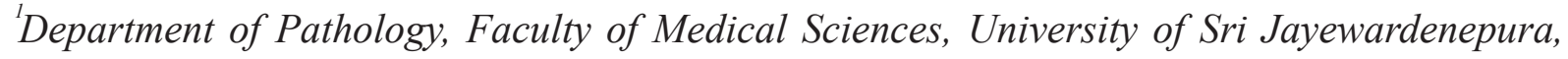
Sri Lanka.

${ }^{2}$ Department of Cellular Pathology, University hospital Birmingham, UK.

Correspondence: Bopagoda TPM, Department of Pathology, Faculty of Medical Sciences, University of Sri Jayewardenepura, Gangodawila, Nugegoda, Sri Lanka. e-mail: tpmbopagoda@gmail.com 
in the investigation of salivary gland disease has been widely debated amongst clinicians and cytopathologists. There is diversity of opinion about its role as a tool in pre-operative evaluation $(4,9)$. Objective To determine the accuracy of fine needle aspiration cytology (FNAC) in the diagnosis of salivary gland lesions.

\section{Materials and methods}

FNAC slides and corresponding histology slides of 96 patients were reviewed. Sensitivity, specificity, diagnostic accuracy, positive and negative predictive value, likelihood ratio and cyto-histological concordance of the FNAC were calculated using histological diagnosis as the gold standard. The diagnostic categories for FNAC and histology are shown in table 1.

\begin{tabular}{|c|c|c|}
\hline $\begin{array}{l}\text { Diagnostic } \\
\text { category }\end{array}$ & FNAC & Histology \\
\hline $\begin{array}{l}\text { Neoplastic } \\
\text { Benign } \\
(\mathrm{NB})\end{array}$ & Benign & Benign \\
\hline $\begin{array}{l}\text { Neoplastic } \\
\text { malignant } \\
(\mathrm{NM})\end{array}$ & Malignant & Malignant \\
\hline $\begin{array}{l}\text { Non } \\
\text { Neoplastic } \\
(\mathrm{NN})\end{array}$ & $\begin{array}{l}\text { Non } \\
\text { neoplastic }\end{array}$ & $\begin{array}{l}\text { Non } \\
\text { neoplastic }\end{array}$ \\
\hline
\end{tabular}

Table 1. Diagnostic categories for FNAC and histology

The definitions used in the statistical analy sis were as follows;

Histological Concordance (C) was defined as FNAC diagnosis which was the same when compared with the histological diagnosis.
Histological Non concordance (NC) was defined as FNAC diagnosis which was not the same when compared with the histological diagnosis.

Deferred Diagnosis was where the presence or absence of malignancy was not stated.

\section{Results}

Of the 96 cases of FNAC 79.2\% (76/96) were benign, 3.1\% (3/96) malignant and for $17.7 \%$ (17/96) the diagnosis was deferred (Table 2). Of the $79.2 \%$ (76/96) benign cases $96.1 \%$ (73/96) were confirmed to be benign on histology but 3.9\% (3/96) were false negative. Of the three false negative cases, two diagnosed as pleomorphic adenomas on FNAC showed one to be adenoid cystic carcinoma and the other a myoepithelial carcinoma on histology. The third diagnosed as a cyst on FNAC, was a mucoepidermoid carcinoma on histology. The three cases which were malignant on FNAC were confirmed to be malignant on histology. Of the 17 cases for which the diagnosis was deferred on FNAC, 64.7\% (11) were benign, $29.4 \%$ (5) malignant and $5.8 \%$ (1) given a deferred diagnosis on histology. Among the 17 FNAC with deferred diagnosis 6 categorised as benign or malignant with adenoid cystic features (Fig 1a,1b \& 2a,2b). Four lesions diagnosed as mucoid cystic lesions on FNAC were diagnosed on histoogy as basal cell adenoma intermediate type, mucoepidermoid carcinoma (Fig 3a\&b), salivary duct carcinoma and a branchial cleft remnant.

The overall rate of deferred diagnosis was $17.7 \%, 15.4 \%$ for non-neoplastic lesions, $45.5 \%$ for malignant tumours and 


\begin{tabular}{|c|c|}
\hline Cytology & Histology \\
\hline \multicolumn{2}{|l|}{ Benign Tumours } \\
\hline 2 Tumour with ACF & 2 Plemorphic Adenoma \\
\hline 1 Small cell salivary gland tumour & 1 Basal cell adenoma \\
\hline 1 Cellular pleomorphic adenoma & 1 Plemorphic Adenoma \\
\hline low grade carcinoma & \\
\hline 1 Mucoid cyst & 1 Basal cell adenoma \\
\hline 2 Tumour with ACF & 2 Myoepithelioma \\
\hline 1 Salivary gland tumour & 1 Plemorphic Adenoma \\
\hline 1 Mucomyxiod lesion & 1 Plemorphic Adenoma \\
\hline \multicolumn{2}{|l|}{ Malignant tumours } \\
\hline 1 Muco-myxoid lesion & 1 Mucoepidermoid carcinoma \\
\hline 1 neoplasm malignancy cannot be excluded & 1 Metastatic melanoma. \\
\hline 1 Epithelial tumour & 1 Oncocytic carcinoma \\
\hline 1 Tumour with ACF & 1 Adenoid cystic carcinoma \\
\hline 1 Mucinous cystic lesion with cellular & 1 Salivary duct carcinoma \\
\hline atypia? Adenoma? low grade & \\
\hline mucoepidermoid carcinoma & \\
\hline \multicolumn{2}{|l|}{ Malignant /Benign tumour } \\
\hline 1 Tumour with ACF & 1 Low grade adenoid cystic carcinoma \\
\hline & Basal cell adenocarcinoma \\
\hline & Myoepithelioma \\
\hline$\underline{\text { Non neoplastic lesions }}$ & \\
\hline 1 squamous cell carcinoma & 1 Chronic sialadenitis \\
\hline 1 Mucoid cystic lesion & 1 Branchial cleft cyst \\
\hline
\end{tabular}

Table 2. Cases of deferred diagnosis 


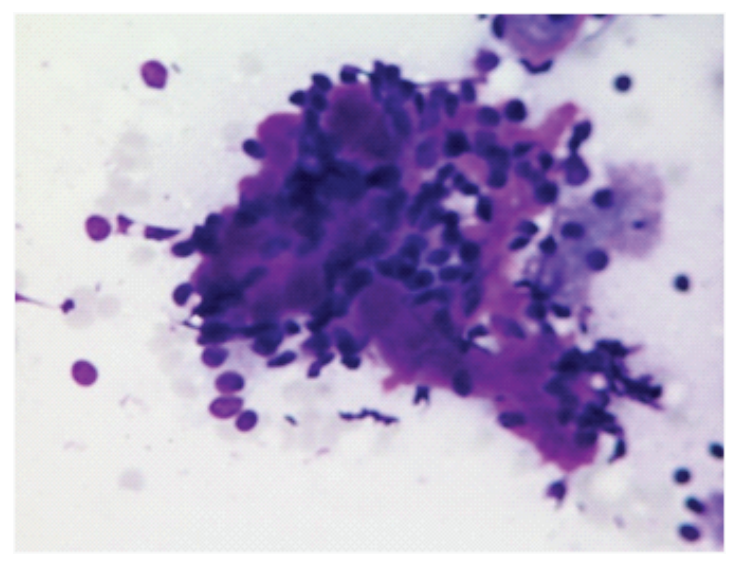

Fig 1a. Adenoid cystic features in pleomorphic adenoma (MGGX40)

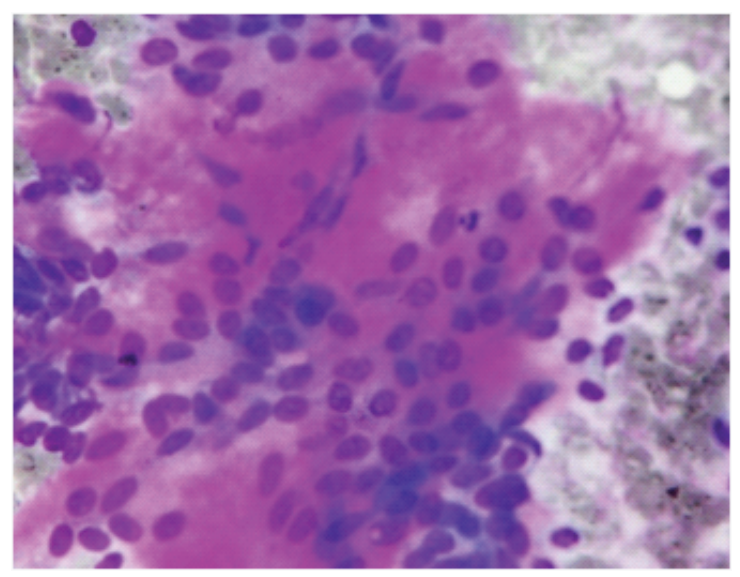

Fig 2a. Myoepithelioma mimicking adenoid cystic like features (MGG X 40)

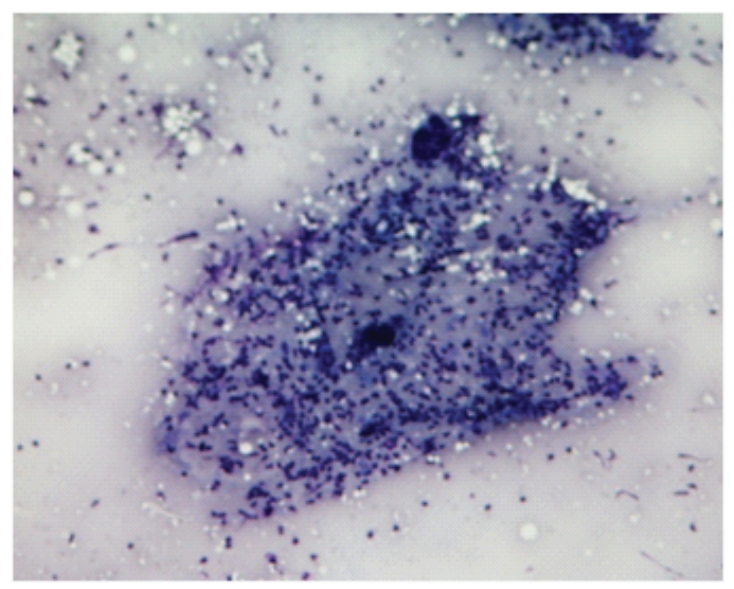

Fig 3a. Mucoepidermoid carcinoma, small cells with little nuclear atypia (PAPX40)

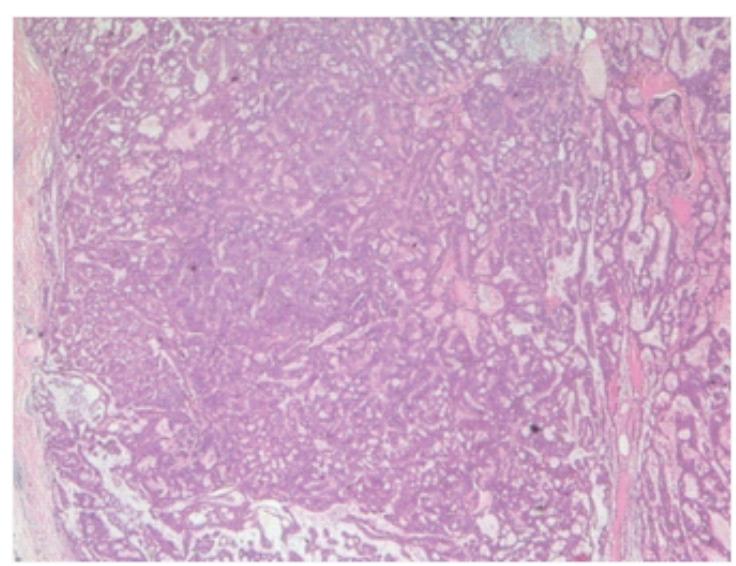

Fig 1b. Pleomorphic adenoma with adenoid cystic areas (H\&EX10)

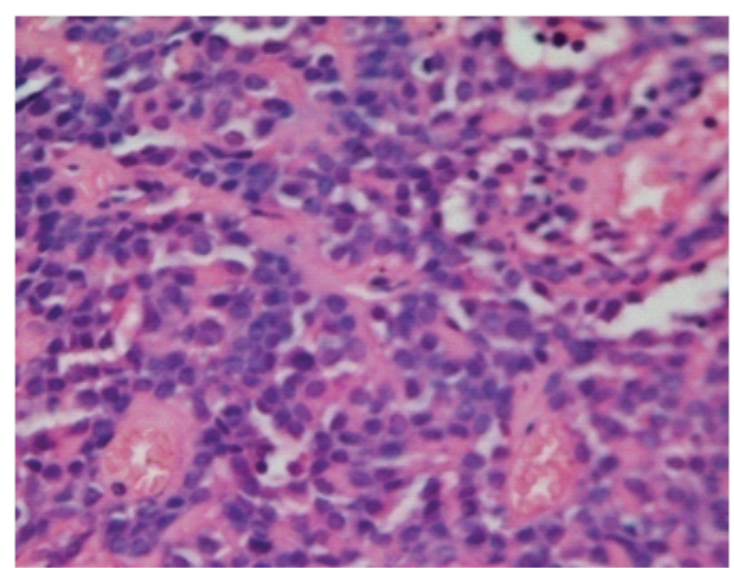

Fig 2b. Myoepithelioma showing hyaline material (H\&E X10)

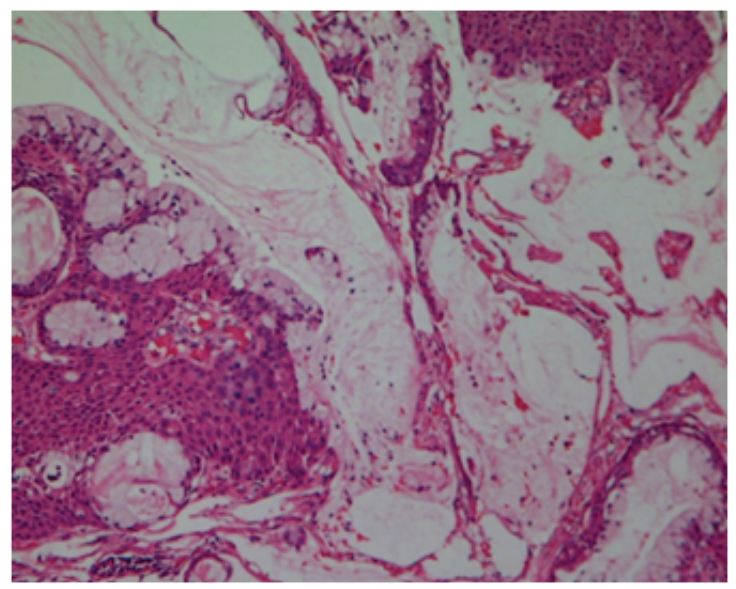

Fig 3b. Mucoepidermoid carcinoma (H\&Ex20) 
$12.7 \%$ for benign tumours. The cytohistological concordance for benign and malignant lesions were $77 \%(65 / 84)$ and 18 $\%(2 / 11)$ respectively and non-concordance was $22.6 \%$ and $9 \%$. When the cases of deferred diagnosis were included, the diag nostic accuracy, sensitivity and specificity of the FNAC in identifying malignancy was $97 \%(76 / 78), 27 \%(3 / 11)$ and $87 \%$ $(73 / 84)$ respectively. When the cases of deferred diagnosis. were excluded the diagnostic accuracy, sensitivity, specificity,

\begin{tabular}{|c|c|c|c|c|c|}
\hline First author & No of cases & sensitivity & $\begin{array}{l}\text { specificity } \\
\text { value }\end{array}$ & accuracy & positive predictive \\
\hline 1)Orell (10) & 325 & 85.5 & 99.5 & - & 98.5 \\
\hline 2)Stewart (11) & 341 & 92 & 100 & 98 & - \\
\hline 3)Al khafaji (12) & 154 & 82 & 86 & 84 & - \\
\hline 4)Schroder (13) & 336 & 93 & 99 & 98.6 & 93.1 \\
\hline 5)Zbaren (14) & 228 & 64 & 95 & 86 & 83 \\
\hline 6)Atula (15) & 218 & 55 & 92 & - & - \\
\hline 7)Van Heerde (16 & ) 294 & 89 & 96 & 93 & 95 \\
\hline 8)Zurrida (17) & 264 & - & - & 87 & 61.1 \\
\hline 9)Cajulis (18) & 151 & 91 & 96 & - & - \\
\hline 10)Hiroyuki (5) & 115 & 88.2 & 100 & 98.2 & - \\
\hline 11)Eric.G (9) & 169 & - & - & - & 84 \\
\hline 12)Lincoln (4) & 68 & 100 & 100 & 89.7 & - \\
\hline 13)Shafkat (19) & 66 & - & - & 98.4 & - \\
\hline 14)Rolf (10) & 380 & 88 & 99 & 96 & 95 \\
\hline 15)Michel (20) & 52 & 66 & 100 & 69.2 & - \\
\hline 16)Elagoz (21) & 162 & 84 & 92 & 78 & - \\
\hline 17)Lu BJ (22) & 113 & - & 92.6 & 90.3 & - \\
\hline Mean & 202 & 82.9 & 96.2 & 89.72 & 87.1 \\
\hline Current study & 96 & 50 & 100 & 96 & 100 \\
\hline
\end{tabular}

Table 3. The diagnostic accuracy in other studies 
positive and negative predictive value and likely hood ratio were $96.2 \%$ (76/79), 50\% (3/6), 100\% (73/73), 100\% (3/3), 96\% $(73 / 76)$ and $50 \%$ respectively. Specificity for diagnosis of benign tumours was $87 \%$ $(62 / 71)$, and the rate of concordance between FNAC and histological diagnosis was $86 \%(61 / 71)$. The sensitivity and cyto-histological concordance for malignant tumours were $27.2 \%(3 / 11)$ and 18\% $(2 / 11)$ respectively. The diagnostic accuracy of FNAC in this study was $96.2 \%$, which was comparable to other studies (Table 3).

\section{Discussion}

The frequency of occurrence of salivary gland tumours in this study was similar to those previously reported $(5,9,10,23)$. The sensitivity and cyto-histological concordance were low for malignant tumours. The deferred diagnosis rate was as high for malignant tumours. Review of the cytology slides of the 3 false negative cases showed the case reported as myoepithelial carcinoma to have a few clusters of epithelial cells with minimal atypia, intermingled with mesenchymal fibrillary material. These low-grade carcinomas are diagnosed by their infiltrative pattern seen on histology and as they do not show high-grade cytological features it is difficult to diagnose them as malignant on cytology. Furthermore the material submitted in this case was suboptimal and this was stated in the report. Of the other two false negative cases, one where adenoid cystic carcinoma was diagnosed as pleomorphic adenoma on FNAC showed scanty magenta basement membrane like fibrillary material inter mingled with epithelial cells which had minimal atypia. However, there were no distinct globules of hyaline material surrounded by epithelial cells, which probably led to the misdiagnosis. Sampling error was evident in the case of mucoepidermoid carcinoma originally diagnosed as a cyst without epithelial sampling on FNAC. The cytological sample showed mucoid material only, without any epithelial cells. Four lesions diagnosed as mucoid cystic lesions on FNAC were diagnosed on histology as basal cell adenoma, intermediate type, mucoepidermoid carcinoma, salivary duct carcinoma and branchial cleft remnant. On review smears from the basal cell adenoma showed copious mucoid material with scattered macrophages, numerous crystals but no epithelial cells. Smears from the brachial cleft remnant, appeared similar with few epithelial cells with atypia. Without adequate epithelial cell sampling it is difficult on an FNAC specimen to assess whether a lesion is benign or malignant.

The histology showed plentiful muco-myxoid and chondro-myxoid stroma with occasional epithelial-myoepithelial tubulo-ductal structures. Review of the smears diagnosed on histology as basal cell adenoma, there were cellular crowded groups and sheets of hyperchromatic ovoid and spindle small cells in a background of scanty mesenchymal material. This made the diagnosis difficult. In the recurrent pleomorphic adenoma; cellular atypia was present on review of the smears. The from the lesion diagnosed on histology as mucoepidermoid carcinoma showed mainly streaks of mucoid debris mixed with numerous lymphocytes and blood. Within this material there were groups of 
small cells with eosinophilic cytoplasm, little nuclear atypia and distinct nucleoli, probably representing intermediate type of cells. Appreciation of the presence of these epithelial cells should have led to the correct diagnosis of this lesion. Review of the smears from the lesion subsequently diagnosed as a salivary duct carcinoma, showed mucoid material, macrophages and poorly preserved atypical epithelial cells and due to the poor preservation of these cells it was difficult to comment on malignancy which occurred in a background of cystic change. In addition, histology showed coexistence of Warthin's tumour within the same gland which probably made cytological interpretation more difficult. Similarly previous studies have shown marked cytomorphological variation that result in significant pitfalls and precluded a specific FNAC diagnosis of salivary duct carcinoma $(23,24)$. A case of pleomorphic adenoma, diagnosed as muco-myxoid lesion on FNAC, on review, showed abundant muco-myxoid material with a few scattered spindle cells only.

The histology showed plentiful muco-myxoid and chondro-myxoid stroma with occasional epithelial-myoepithelial tubulo-ductal structures. Review of the smears diagnosed on histology as basal cell adenoma, there were cellular crowded groups and sheets of hyperchromatic ovoid and spindle small cells in a background of scanty mesenchymal material. This made the diagnosis difficult. In the recurrent pleomorphic adenoma; cellular atypia was present on review of the smears. The diagnostic difficulty can arise due the presence of low-grade malignancy with weak cellu lar atypia, existence of various histological types and co-existence more than one tumour type. To improve the accuracy of diagnosis it is necessary to reaspirate the solid areas after aspiration of the cyst fluid. Diagnostic accuracy can also be improved when done by a clinician experienced in sampling $(7,25,26)$. In addition repeated, preferably ultrasound guided FNAC is advocated (26).

\section{References}

1. Leon Barnes, John W Eveson, Peter Reichart, David Sidransky. Pathology and genetics of head and neck tumours. IARC press, Lyon 2005. 209-281.

2. Rosai and Ackerman's surgical pathology. 9th Edition. Volume II Mosby Edinburgh, London, New York Philadelphia, St Louis, Sydney, Toronto 2004. 873-916.

3. Cheuk W, Chan J K C, Salivary gland tumours, Christopher DM Fletcher. Diagnostic Histopathology of Tumours. 3rd Edition, Churchill livingstone. 2007; 239-325.

4. Lincoln GL Tan, Mark LC Khoo. Accuracy of fine needle aspiration cytology and Frozen section histopathology for lesions of the major salivary glands. Annals Academy of Medicine Singapore 2006; 35: 242- 4.

5. Hiroyuki Mihashi, Akihiko Kawahara, Masayoshi Kage, Masamichi Kojiro, Tadashi Nakasima, Hirohito Umeno, Kikuo Sakamoto, Hideki Chiziwa. Comparison of Preoperative Fine Needle Aspiration Cytology Diagnosis and Histopathological Diagnosis of Salivary Gland Tumours. Kurume Medical Journal 2006; 53: 23-27.

6. Cuanxian Zhang, Jean- Marc Cohen, Joan F. Cangiarella, Jerry Waisman, Barbara J Mckenna, 
Journal of Diagnostic Pathology 2012 (7); 1: 50-58

and David C, Chhieng. American Journal of Clinical Pathology 2000; 113: 21-28.

7. J A Young. Diagnostic problems in fine needle aspiration cytology of salivary glands. Journal of Clinical Pathology 1994; 47: 193-198.

8. Christian Lussier, Jerzy Kijanienko, Philippe Vielh, Fine Needle Aspiration of Metastatic Non lymphomatous Tumours to the Major Salivary Glands Cancer Cytopathology 2000; 90: 350-56.

9. Eric G. Cohen, Snehal G. Patel, Oscar Lin, Jay O Boyle, Dennis H Kraus, Bhuvanesh Singh, Richard J. Wong, Jatin P. Shah, Ashok R.Shaha. Fine Needle Aspiration Biopsy of salivary gland lesions in a Selective Population. Archives of Otolaryngolology Head and Neck Surgery Volume 130, June 2004.

10. Orell SR. Diagnostic difficulties in the interpretation of fine needle aspirates of salivary gland lesions: the problem revisited. Cytopathology 1995; 6: $285-300$.

11. Stewart CJ, MacKenzie K, McGarry GW, MowatA. Fine needle aspiration of salivary : a review of 341 cases. Diagnostic Cytopathology 2000; 22: 139-146.

12. Al-Khafaji BM, Nestok BR, Katz RL. Fine needle aspiration of 154 parotid masses with histologic correlation. Cancer. 1998; 84: 153-159.

13. Schroder U, Eckle HE, Rasche V, Arnold G, Ortmann M, Stennert E. Wertigkeit der Feinnadelpunktionszytolodie bei Neoplasien der Glangula Parotis. (HNO Hals, Nasen, Ohren-Heilkunde) ENT ( German) 2000; 48; 421-429.

14. Zbaren P, Schar C, Hotz MA, Loosli H. Value of fine needle aspiration cytology of parotid gland masses. Laryngoscopy 2001; 111: 1989-1992.
Validity of fine needle aspiration cytology in the diagnosis of salivary gland lesions

15. Atula T, Gernman R, Laippala P, Klemi PJ. Fine needle aspiration biopsy in the diagnosis of parotid gland lesions: evaluation of 438 biopsies. Diagnostic Cytopathology 1996; 15: 185-190.

16. Van Heerde P, Peterse JL. Fine needle aspiration cytology of salivary glands. Head and neck 1993; 18: 187- 195.

17. Zurrida S, Alasio L, Tradati N, Bartoli C, Chiesa F, Pilotti S. Fine needle aspiration of parotid masses. Cancer 1993; 72: 2306-2311.

18. Cajulis RS, Gokaslan ST, Yu GH, Frias- Hidvegi D. Fine needle aspiration biopsy of the salivary gland. A five-year experience with emphasis on diagnostic pitfalls. Acta cytologica 1997; 41; 1412 1420.

19. Shafkat Ahrnad, Mohainmad Lateef, Rouf Ahamad. Clinicopathological study of primary salivary gland tumours in Kashmir JK Practitioner 2002; 9(4): 231-233.

20. Michel Luri, Inesh Misselevitch,Milo fradis. Diagnostic value of fine needle aspiration from parotid gland lesions. Israel Medical Association Journal 2002; 4: 681-683.

21. S.Elagoz, M. Gulluoglu, D. Yilmazbayhan, H.ozer, I. Arslan. The value of fine needle aspiration cytology in salivary gland lesions, 1994- 2004. Journal Oto-Rhino-Laryngology, Head and Neck Surgery 2007; 69(1): 51-6.

22. LuBJ, Zhu J, Gao L, Xie L, Xu JY, Lai . Diagnostic accuracy and pitfalls in fine needle aspiration cytology of salivary glands: a study of 113 cases. Chinese Journal of Pathology 2005 November; 34(11): 706-10.

23. Kelly K. Dosmon, Paul E, Wakely. Aspiration and Imprint Cytology of Salivary Duct Carcinoma. Cancer Cytopathology 1997; 81: 281-6. 
24. Kamal K. Kuhurana, Martha B.Pitman, Celeste N. Powers, Sihelia Korourian, Ricardo H. Bardales, Michael W Stanley. Diagnostic Pitfalls of Aspiration cytology of Salivary Duct Carcinoma. Cancer Cytopathology 1997; 81: 373-8.

25. Joseph F. Nasuti, Gordon H. Yu, Prabodh K. Gupta. Fine-Needle Aspiration of Cystic Parotid Gland Lesions. Cancer Cytopathology 2000; 90 : 111-6.

26. Fied R, Nazarian LN, Needleman L et al Clinical impact of sonographically guided biopsy of salivary gland masses and surrounding lymph nodes. Ear Nose Throat Journal 1999; 78: 905,908-912. 